\section{Gating of optical multichannel analysers with krytron switches}

\author{
J Biebl and A Penzkofer \\ Fakultät für Physik der Universität Regensburg, \\ 8400 Regensburg, Germany
}

Received 5 March 1980

Abstract A krytron pulse generator is used to gate an optical multichannel analyser. The pulse generator circuit is described and the performance of gating is analysed.

\section{Introduction}

Optical multichannel analysers consisting of a detector array and a signal processing console have proved to be powerful detection systems. The gating of the detector heads facilitates their use in studies with picosecond and nanosecond light signals due to reduction of background light (Dörr et al 1976, Ostertag 1977). Rather expensive gating pulse generators are offered by the manufacturers of optical multichannel analysers (e.g. model PARC 1211 by Princton Applied Research and model BM 5800 by B \& M Spectronic). Here we describe an inexpensive krytron pulse generator and analyse its gating performance.

\section{Description of krytron pulse generator}

The optical multichannel analyser OSA 500 (B \& M Spectronic) used in our experiments needs a negative high voltage pulse for gating. A krytron system is built-up to generate the required pulses.

Figure 1 depicts the circuit of the krytron system. It consists of four parts, the trigger section, the avalanche transistor chain, the krytron tube and the output pulse stage (Ley et al 1970, Hyer et al 1975, Cunin et al 1977). The trigger transistor $Q_{1}$ is switched by a positive voltage signal of $1.5 \mathrm{~V}$ (duration $\gtrsim 5 \mathrm{~ns}$ ) to $5 \mathrm{~V}$ (duration $\simeq 0.5 \mathrm{~ns}$ ). The collector-emitter voltage of transistor $Q_{1}$ is regulated near to its breakdown voltage $(\approx 200 \mathrm{~V})$ with resistors $R_{3}$ and $R_{7}$ (Ryder-Smith 1961). Voltage divider $R_{4}, R_{5}$ generates a synchronisation pulse of about $5 \mathrm{~V}$ after switching of $Q_{1}$ (time delay $\approx 5 \mathrm{~ns}$ ). The voltage across the avalanche transistors $Q_{2}-Q_{7}$ is fixed to $V_{\text {in }}=350 \mathrm{~V}$ (breakdown voltage $\approx 360 \mathrm{~V}$ ). Transformer $\mathrm{T}_{1}$ generates the firing signal for the avalanche transistor chain and the capacitors are discharged (Bell 1964, Henetry 1961, Lundy and Parker 1978, Martin and Kuizenga 1978). A high voltage pulse is formed $(\approx 2000 \mathrm{~V})$ which switches the krytron KR (type KN22 of EG \& G Electro-optics division) into the contacting state. The keep-alive current of the krytron is regulated to $300 \mu \mathrm{A}$ with resistor $R_{23}$. At the sockets $S_{1}$ and $\mathrm{S}_{2}$ a cable $\mathrm{L}_{\mathrm{G}}$ of length $l_{\mathrm{G}}$ is connected. It is loaded from the high voltage power supply $\mathrm{HV}_{\text {in }}$ through the recharging resistor $R_{24}$ and the two impedance matching resistors $R_{25}$ and $R_{26}$. The transmission line $\mathrm{L}_{\mathrm{G}}$ is discharged when the krytron is brought to the contacting state. During the discharge the transformer $\mathrm{T}_{2}$ generates a negative output voltage pulse $V_{\text {out }}$ which is used for gating. The cable length $l_{\mathrm{G}}$ determines the gate width $t_{\mathrm{G}}\left(t_{\mathrm{G}}=l_{\mathrm{G}} / v ; v \approx 200 \mathrm{~mm} \mathrm{~ns}^{-1}\right)$. The time delay between trigger input at $\operatorname{Tr}_{\text {in }}$ and the onset of the output pulse

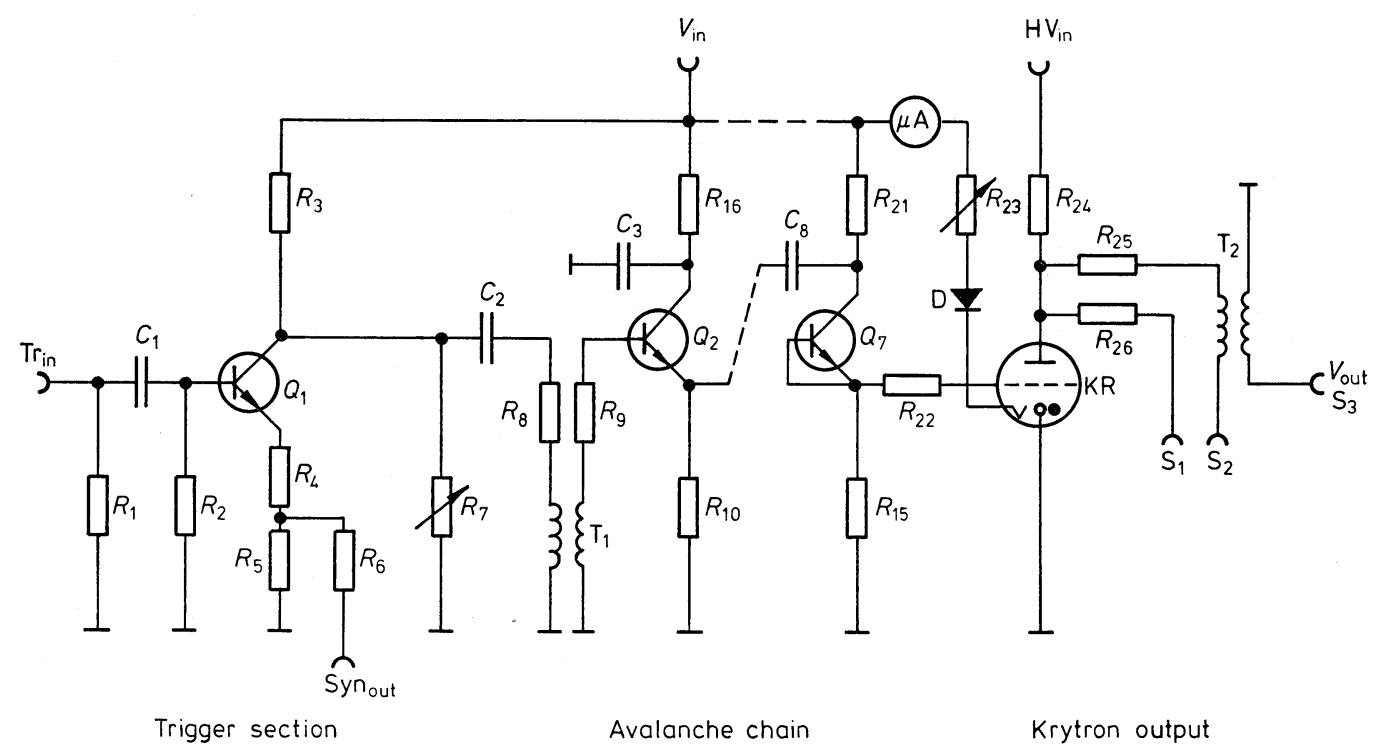

Figure 1 Krytron pulse generator. Resistors: $R_{1}=1 \mathrm{k} \Omega$, $R_{2}=47 \Omega, R_{3}=510 \mathrm{k} \Omega, R_{4}=50 \Omega, R_{5}=1 \cdot 5 \Omega, R_{6}=50 \Omega$, $R_{7}=680 \mathrm{k} \Omega, R_{8}=47 \Omega, R_{9}=56 \Omega, R_{10}$ to $R_{21}=150 \mathrm{k} \Omega$, $R_{22}=50 \Omega, R_{23}=910 \mathrm{k} \Omega, R_{24}=40 \mathrm{M} \Omega, R_{25}=R_{26}=45 \Omega$. Capacitors: $C_{1}=100 \mathrm{nF}, C_{2}$ to $\mathrm{C}_{8}=2 \cdot 2 \mathrm{nF}$. Transistors: $Q_{1}, 2 \mathrm{~N} 3700$ (National semiconductors); $Q_{2}$ to $Q_{7}, 2 \mathrm{~N} 5551$
(Motorola). Diode D, 5AV60 (International Rectifier). Transformers: $T_{1}$, core Ferroxcube FXC $3 \mathrm{~B}$ damping pearl (Valvo), turns ratio $1: 1,4$ turns. $\mathrm{T}_{2}$, ring core Ferroxcube FXC 3H1 (Valvo), for dimension see text. Krytron KR, KN22 (EG \& G). Four avalanche transistor stages are omitted. 
at $S_{3}$ was found to be $40 \mathrm{~ns}$ with a jitter of \pm 2 ns. Resistor $R_{22}$ and high voltage diode $\mathrm{D}$ protect the avalanche transistor chain from damage due to feed-back from the grid of the krytron.

Figure 2(a) shows output voltage pulses from the krytron pulse generator for a cable length of $l_{\mathrm{G}}=10 \mathrm{~m}$ and various input voltages $\mathrm{HV}_{\text {in. }}$ A ring core Ferroxcube $\mathrm{FXC} 3 \mathrm{H} 1$ (Valvo) with $23 \mathrm{~mm}$ outer diameter, $14 \mathrm{~mm}$ inner diameter and $7 \mathrm{~mm}$ height was used for transformer $\mathrm{T}_{2}$ (primary 3

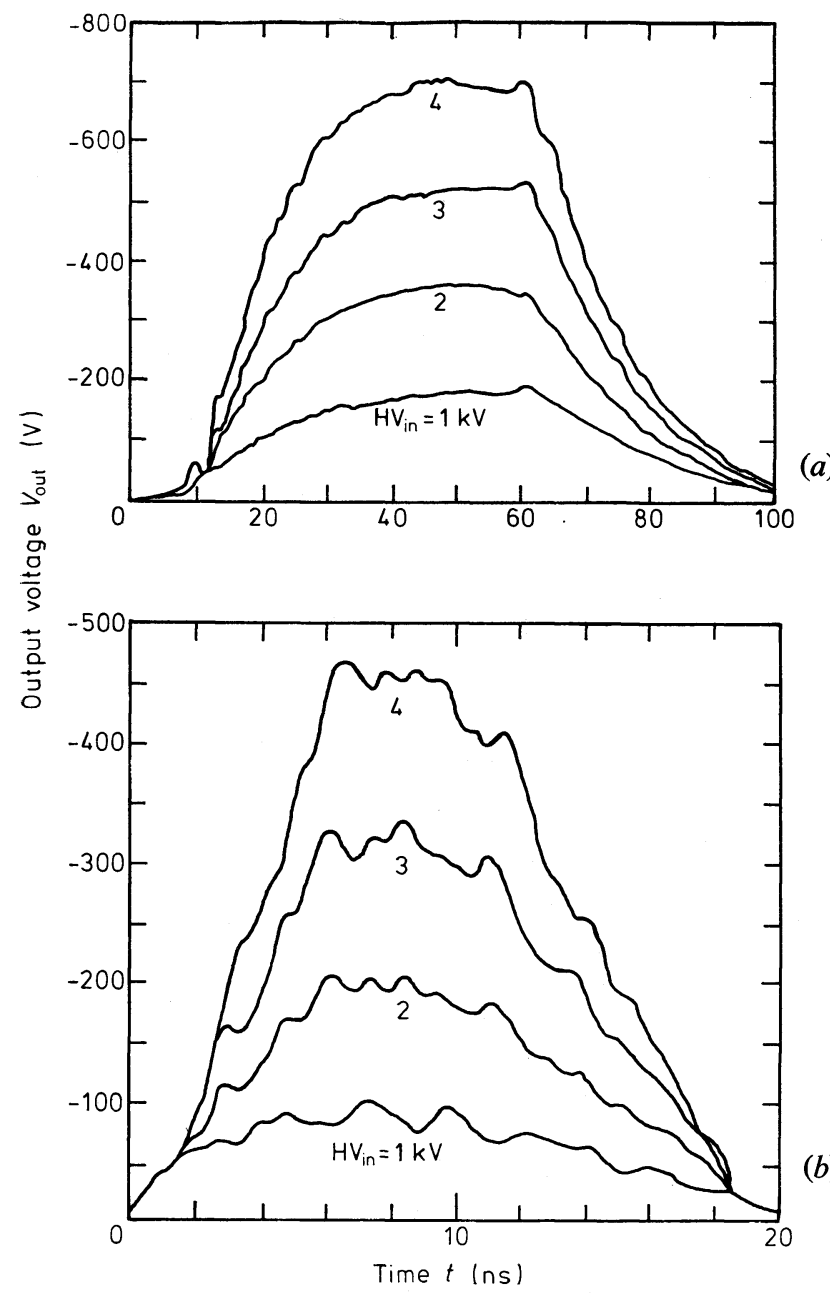

Figure 2 Voltage pulses of krytron pulse generator. $V_{\text {out }}$ is measured across $50 \Omega$. (a), Dimension of transformer ring core $T_{2}$ : outer diameter $d_{\mathrm{a}}=23 \mathrm{~mm}$, inner diameter $d_{\mathrm{i}}=14 \mathrm{~mm}$, height $h=7 \mathrm{~mm}$. Cable length $l_{\mathrm{G}}=10 \mathrm{~m}$. (b), Transformer dimensions $d_{\mathrm{a}}=14 \mathrm{~mm}, d_{\mathrm{i}}=9 \mathrm{~mm}$, $h=5 \mathrm{~mm}$. Cable length $l_{\mathrm{G}}=1 \mathrm{~m}$.

turns, secondary 8 turns). The output voltages $V_{\text {out }}$ were measured across a $50 \Omega$ load with a transient digitiser (Tektronix $7912 \mathrm{AD}$ ). At input voltages $\mathrm{HV}_{\text {in }}>4 \mathrm{kV}$ the output voltages begin to saturate $\left(V_{\text {out, }} \max \approx-800 \mathrm{~V}\right.$ across $50 \Omega$ ). The rise and decay time of the output pulses is $11 \mathrm{~ns}$. By adjusting the cable length $l_{\mathrm{G}}$ the gate pulse width could be varied between $20 \mathrm{~ns}$ and $200 \mathrm{~ns}$.

Figure 2(b) depicts output voltage pulses obtained with a smaller transformer core (Ferroxcube FXC 3H1) of $14 \mathrm{~mm}$ outer diameter, $9 \mathrm{~mm}$ inner diameter and $5 \mathrm{~mm}$ height (turns ratio $1: 1,3$ turns). A cable length of $l_{G}=1 \mathrm{~m}$ was used. The rise and decay times of the pulses reduce to $5 \mathrm{~ns}$ and a pulse width (FWHM) of $12 \mathrm{~ns}$ is obtained. The output voltage saturates to $V_{\text {out, } \max } \approx-500 \mathrm{~V}$ for high input voltages of $\mathrm{HV}_{\text {in }} \gtrsim 5 \mathrm{kV}$.

A krytron system with the same circuit as shown in figure 1 was also used to trigger a Pockels cell shutter for single pulse selection from a mode locked ruby laser (Billman and Burnham 1970, Ley et al 1970, Hyer et al 1970). Only at the output section the transformer $\mathrm{T}_{2}$ was removed and two charging lines $L_{1}$ and $L_{2}$ leading to the Pockels cell were connected at $\mathbf{S}_{1}$ and $\mathbf{S}_{2}$ (see figure 3 ).

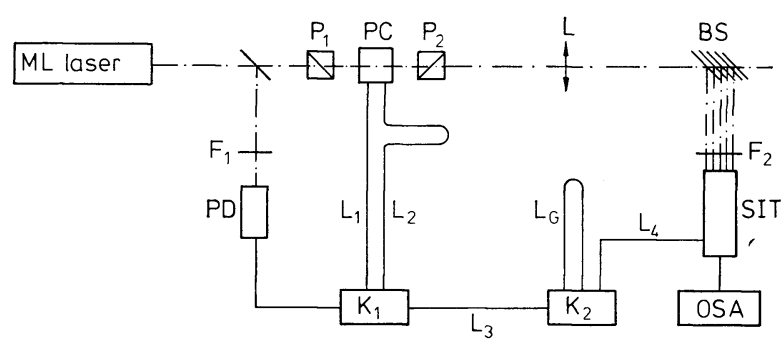

Figure 3 Experimental setup. $\mathrm{P}_{1}, \mathbf{P}_{2}$ Glan polarisers; PC Pockels cell; L lens $(f=1 \mathrm{~m})$; BS stack of planparallel glass plates; $F_{1}, F_{2}$ filters; PD photodetector; $K_{1}, K_{2}$ krytron pulse generators; $\mathrm{L}_{1}-\mathrm{L}_{4}, \mathrm{~L}_{\mathrm{G}}, 50 \Omega$ coaxial cables RG58C/U; SIT, silicon intensified target vidicon; OSA, console of optical spectrum analyser.

The described circuit allows high repetition rates up to $50 \mathrm{~Hz}$. The repetition rate is limited by the recharging time of the transmission lines and by the recovery time of the krytron tube (EG \& G data sheet $\mathrm{K}$ 5500B-2).

\section{Experimental system}

The experimental setup for testing the synchronised gating of the SIT tube (Thompson CSF TH 9659 nocticon) of the OSA 500 system is shown in figure 3 . Trains of picosecond light pulses are generated by a passively mode locked ruby laser (see e.g. Shapiro 1976). A single pulse is selected from the pulse train with an electrooptic shutter consisting of a Pockels cell PC (type PC105 of Electro-optic developments) and crossed Glan polarisers $P_{1}$ and $P_{2}$. The Pockels cell is operated by krytron system $\mathrm{K}_{1}$ (see above) which is triggered by the output signal of photodetector PD. The separated light pulse is focused with lens L and split into an array of beams with a series of glass plates BS. Filter $\mathrm{F}_{2}$ in front of the SIT tube reduces the intensity of the light beams. The SIT tube is gated by the krytron pulse generator $\mathrm{K}_{2}$ which is triggered by the synchronisation output signal of krytron system $\mathrm{K}_{1}$. The difference of the cable lengths $l_{3}+l_{4}-l_{1}$ determines the gate-on position of the SIT tube with respect to the opening moment of the Pockels cell shutter. A short length of $l_{4} \approx 10 \mathrm{~cm}$ was used to avoid problems of impedance matching of cable $\mathrm{L}_{4}$ to the SIT tube.

\section{Performance of gating}

The gating performance of the optical multichannel analyser is presented in figure 4.

The voltage $V_{\text {out,opt }}$ for optimum gating varies with gate width $t_{\mathrm{G}}$ (figure $\left.4(c)\right)$. For $t_{\mathrm{G}}=12 \mathrm{~ns}\left(l_{\mathrm{G}}=1 \mathrm{~m}\right.$, small transformer core, see figure $2(b))$ a voltage of $V_{\text {out, opt }}=-450 \mathrm{~V}$ was necessary to obtain a sharp picture while at $t_{\mathrm{G}}=50 \mathrm{~ns}$ $\left(l_{\mathrm{G}}=10 \mathrm{~m}\right) V_{\text {out}}$, opt reduced to $-220 \mathrm{~V}$. The opening time of the SIT tube was found to be approximately equal to the gate duration. 

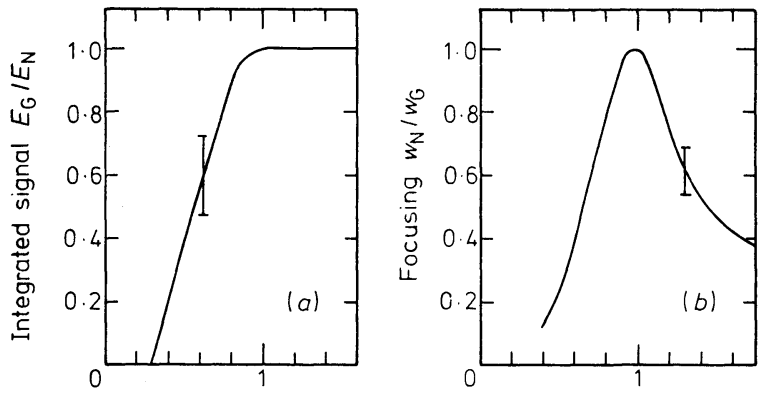

Gate pulse voltage $V_{\text {out }} / V_{\text {out }}$ opt
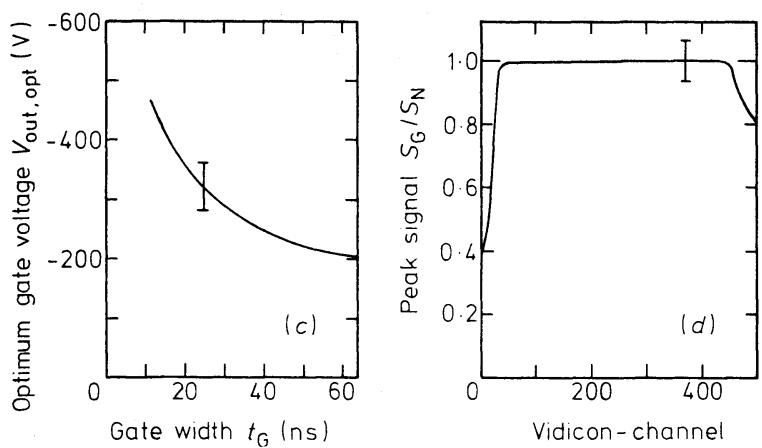

Figure 4 Performance of OSA gating. (a), Total OSA signal against gate pulse voltage $V_{\text {out }}$ normalised to ungated operation. $(b)$, Beam focusing of SIT tube against $V_{\text {out }} w_{\mathrm{N}}$ ungated signal width (6 channels), $w_{\mathrm{G}}$ gated signal width. (c), Optimum gate voltage against gate width (FWHM). (d), Signal height across the target normalised to ungated situation.

The total signal $E_{\mathrm{G}}$ integrated over all elements of the diode array of the SIT tube is shown in figure $4(a)$ as a function of gate pulse voltage $V_{\text {out }}$. The integrated signal is normalised to the total signal $E_{\mathrm{N}}$ obtained by ungated operation. Optimal signal throughput is obtained for $V_{\text {out }} \geq V_{\text {out, opt }}$.

The focusing of the tube is analysed in figure $4(b)$. An array of 18 focused laser beams was incident to the photocathode of the tube. The width of a single beam at the cathode was $150 \mu \mathrm{m}$ (measured with ungated SIT tube, six channels). The ratio of the signal widths at normal operation $w_{\mathrm{N}}$ to gated operation $w_{\mathrm{G}}$ is depicted. At $V_{\text {out, opt }}$ the gated tube produces the same sharp signals as the ungated tube $\left(w_{\mathrm{N}} / w_{\mathrm{G}}=1\right)$. For higher and lower voltages the detected signals broaden.

The signal heights of the array of light beams across the detector target were compared at optimum focusing conditions $\left(V_{\text {out, opt }}\right)$ with the ungated situation. Figure $4(d)$ shows the ratio of the signal peaks obtained by gating $S_{G}$ to the signal peaks $S_{N}$ measured without gating. For the vidicon channels 30 to 470 signal heights are not modified $\left(\mathrm{S}_{\mathrm{G}} / \mathrm{S}_{\mathrm{N}}=1\right)$. Only at the edges (channels $0-30$ and 470-499) the signal height is reduced by gating.

\section{Conclusion}

The described krytron pulse generator operates reliably for gating of an optical multichannel analyser. With a slight modification at the output stage the krytron system was also successfully applied to single pulse selection from a picosecond laser with a Pockels cell shutter. Without gating, optical multichannel analysers integrate light signals up for a duration of about $0.1 \mathrm{~s}$ in single shot experiments. The described gating reduces the integration duration down to the ns range. It allows the operation of optical multichannel analysers at day light with increased signal-to-noise ratio. The discrimination between light signals of different duration or occurring at different times is made possible.

\section{Acknowledgments}

The authors thank Professor M Maier and G Gössl for valuable discussions. Technical assistance of $T$ Ascherl is gratefully acknowledged.

\section{References}

Bell B H 1964 Avalanche circuits are more versatile than you think

Electronic Design June p 56-63

Billman K W and Burnham D C 1970 Photodetector triggered pulse selection from a mode locked ruby laser Rev. Sci. Instrum. 41 1837-8

Cunin B, Miehé J A, Schelev M, Sipp B, Thébault J 1977 Performance of sweep devices used in picosecond image converter cameras

Conference on detection and analysis of picosecond light phenomena, April 21-22, Centre de recherches nucleaires, Strasbourg

Dörr F, Hub W, Schneider S and Taylor J R 1975

Application of a negative hv square-wave generator for gating of image intensifier tubes

EMI application note R/S 019

Henetry W M 1961 Avalanche transistor circuits Rev. Sci. Instrum. 32 1198-203

Hyer R C, Sutphin H D and Winn K R 1975

Laser-initiated krytron-switched Blumlein-switched structure for pulse selection

Rev. Sci. Instrum. 46 1333-4

Ley J M, Eng C, Christonas T M and Wildey C G 1970 Solid state subnanosecond light switch

Proc. IEE 117 1057-62

Lundy A and Parker J R 1978 Avalanche transistor pulser for fast gated operation of multichannel plate image-intensifiers

IEEE Trans. Nucl. Sci. NS-25 591-7

Martin W E and Kuizenga D J 1978 Laser components in: Laser program annual report - 1977, Lawrence Livermore Laboratory, Livermore, Calif. UCRL-50021-77 p 2.16-2.22

Ostertag E 1977 Full synchronisation of an optical multichannel analyser for picosecond spectroscopy Rev. Sci. Instrum. 48 18-23

Ryder-Smith S C 1961 Voltage breakdown of transistors Electronic Technology October 348-56

Shapiro S L 1976 Ultrashort Light Pulses (Berlin: Springer) 